\title{
Media Awareness on Diseases From Pollution - A Study of Silchar Town in Southern Assam, India
}

\author{
Parthia Sarkar \\ Department of Mass Communication, Assam University Silchar \\ e-mail: parthasarkarsil@gmail.com
}

\begin{abstract}
Exposures to environmental toxicants have always been a major source of health risks throughout the world. Pollution is thus a threat to human health, the environment and the quality of life of millions of lives on this planet. Since the last decade, media has become a major source in promoting health awareness. They provide knowledge about how to prevent and overcome from these diseases. The media matter significantly in public health. It affects the mind of the people as well as their thinking process and ideas. It is a major force in creating awareness about important issues and affects national and global efforts towards socio-economic progress and understanding. This descriptive cross sectional study was conducted to determine the awareness level and knowledge of the people of Silchar about pollution diseases and various health problems arising out of it.
\end{abstract}

Keywords: Environmental Toxicants, Health, Pollution, Media Awareness

\section{INTRODUCTION}

Today, the threat to our environment has increased manifold with toxic and radioactive pollutants dumped untreated in it which in turn has lethal consequences not only on the environment but also on the entire bio-system in this planet. Thus the environmental pollution has become an important global issue. The natural resources which are vital for life on this planet are severely contaminated which contribute to health problems and lower quality of life. Media today has a great impact on people of all ages. It has a vital role to play in this area as there is a overwhelming need for creating massive awareness among people about this pollution and the precautionary measures to combat it. Mass media can play an important role in creating awareness along with all-out support of the people in the society. Thus this research paper is an attempt to find out the level of awareness of the people of Silchar about the pollution related diseases and their impact on their life.

Silchar is considered as the headquarter of southern Assam . It is one of the most populated and also one of the most polluted town of north-east India having large number of people suffering from pollution related diseases. In Silchar town, a large number of people suffer from respiratory, skin and water-borne diseases. The town of Silchar, the second largest city in the state has a overwhelming numbers of registered vehicles contributing to air pollution with many brick factories and stone crushers. The city has no proper sewerage system and the drain water comes on road in every rainy season. In adequate maintenance of the drinking water pipes causes the problem of 
water borne pollution, which is reflected through some $60 \%$ of water borne diseases cases registered every year.

Since mass media plays a central role in disseminating scientific and medical knowledge to the general public, it can significantly contribute to the construction of campaigns on social problems in the public arena. How far the people of Silchar are aware about the pollution and health problems they face due to this is still unknown. This study provides a systematic analysis of the awareness level of the residents of the town and how much the media is responsible for the awareness.

The Objective of the study are:

a. To know the socio-economic background of the respondents;

b. To understand the media habit of the people of Silchar;

c. To understand the relationship between the level of awareness and exposure to mass media.

\section{RESEARCH METHODS}

The aim of the study is to examine the role of media in promoting awareness about pollution and related diseases among the people of Silchar. To get a representative picture about the objectives of this study, cross sectional survey has been done among the sample of the population. Questionnaire and schedule were utilized to gather information from the respondents. For the proposed study, the population of the Silchar Municipal Jurisdiction has been taken as the universe of this research. As per Silchar Municipality Board, there are 28 wards and all the blocks are taken for study. The ward no. 22 is selected by random sampling method. Method) . 100 respondents were drawn from this ward by systematic sampling method. The available voter list had household no. which accounted for 929 no. of houses in this ward. The total number of household was divided by total sample size (i, e.100) to get the ninth no of house, which was taken as the sample. Only one member of the household was administered with the questionnaire.

\section{Operational Definition}

1) Pollution: It is the introduction of contaminants into an environment that causes instability, disorder, harm or discomfort to the ecosystem i.e. physical systems or living organisms

2) Health: The World Health Organization (WHO), in 1948, defined Health as being "a state of complete physical, mental, and social well-being and not merely the absence of disease or infirmity".

3) Mass Media . related to the following forms of mass communication

a. Print media: newspapers, magazines, brochures, books, journals, etc

b. Electronic media: radio, television, video shows, internet, etc.

\section{FINDING AND DISCUSSION}

The key findings on socio-economic background, mass media habits, awareness about environmental pollution and related public health may be summarized as follows:

\section{Socio-economic Background}

1) In terms of age group 15 percent respondents belong to the age group 15-20 years, 53 percent belong to the age group 20-40 years, 28 percent belong to the age group 40-60 years and only 4 percent respondents belong to the age group of above 60 years. 
2) In terms of educational qualification of the respondents, only 3 percent of the respondents are illiterate . majority of the respondents i,e 26 percent are graduates, followed by 22 percent professionals (MBBS, LLB, B. Tech, MBA, MCA, MMC, M.Phil, Ph. D and others ), 18 percent post graduates, 11 percent has technical qualification (Diploma Holder from polytechnic! ITI, etc.) , 11 percent H. S. ,5 percent Primary and 4 percent are High School pass.

3) In terms of occupation of the respondents, 8 percent of the respondent are housewives, 23 percent Govt. employee (both retired and presently working) ,5 percent professional (Doctors! Engineers! Lawyers, etc.), 21 percent PSU (both retired and presently working), Bank(both retired and presently working) and MNC (both retired and presently working) employees ( Sales personnel, private Bank employee, etc.), 10 percent business person, 1 percent self employed, 5 percent private firm employee(both retired and presently working), 5 percent unskilled labors (daily wager/ housemaid! helper), 14 percent student, 7 percent unemployed, and one percent others(small shopkeeper).

4) The data reveal that 36 percent of the respondents are of upper medium income group (Rs. 24001-30000), 27 percent from the medium income group (Rs 16001 24000),21 percent are from the high income group Rs. 30000 and above) , 11 percent from medium i income group(Rs.8001- 16000) and 5 percent from low income group below Rs. 8000).

5) Since the respondents live in urban area, the source of drinking water is Municipal Supply water for 98 percent respondents, 1 percent drink water from tube well and 1 percent from pond.

6) Majority of the respondent cook food in LPG stoves, 9 percent in kerosene stove and one percent in Chulha.

\section{Media Habits}

1) Majority of the respondents read and subscribe newspaper. It is interesting to note that 93 percent of the respondents who read newspaper Dainik Jugasankhya has the largest readership with 89 respondent, Samaik Pasanga is read by 71 respondents, Ananda Bazar Patrika by 41 respondents, Times of India by 33 respondents, The Statesman by 12 respondents, The Telegraph by 29 respondents The Hindu by 5 respondents, The Assam Tribune by 32 Respondents, Employment news by 15 respondents and others by 23 respondents.

2) Among the respondents, majority (78 percent) read current affairs, 63 percent read first page news, 22 percent read only headlines, 49 percent read Zodiac sign, 61 percent read politics, 81 percent read sports news, 54 percent read health related matter, 66 percent read advertisement, and 42 percent read reader's column, 12 percent read matrimonial, 22 percent read

3) As per reading habits, 7 percent does not read newspaper, 12 percent read read 223 days in a week, 22 percent read 4-6 days in a week, 43 percent daily and 16 percent read once in a week.

4) The data also reveal that 93 respondents who read newspaper, majority read for 2 hours( i.e. 66 percent), 4 percent for half an hour, 22 percent for 1 hour, and 8 percent for more than 2 hours.

5) Among the respondents only 3 percent do not have a television set in their home but only 2 do not watch T.v. at all. Most of the respondents watch television regularly accounting to 95 percent who watch television. 
6) Among the respondents 71 percent like to watch serials, while 74 percent like to watch reality shows, news are viewed by 54 percent of the respondents sports program are viewed by 68 percent of the respondents. .i.e TV $\mathrm{h}$ viewership with 57 percent. Local channels have 44 percent viewership.

7) In terms of digital literacy 87 percent of the respondents know how to operate computer. The main purpose of using internet is business for 21 percent, entertainment and games for 69 percent and 23 percent for education. The most visited site of the respondents are Google, Facebook, Twitter, YouTube and eBay.

8) Regarding the radio listening habits 68 percent of the respondent do not have radio sets and only 32 percent respondents have radio sets. Of the 32 percent respondent only 23 respondents listen to radio and that also for not more than a hour. They mainly listen to local news, and sports commentary. Other programs that are listened to by the respondents are news, drama, songs, chat shows.

\section{Media on Pollution Awareness}

1) In terms of awareness about pollution ,78 percent of the respondent ascertained that they had read news/ articles/columns/ ads/ other items related to air pollution but only 31 percent of the 78 percent could recall properly. About water pollution 52 percent had read news/ articles/columns/ ads/ other items related to water pollution but only 37 percent could recall. About soil pollution 72 percent had read news/ articles/columns/ads/ other items related to soil pollution but only 29 percent could recall. About noise pollution 18 percent had read news/ articles/columns/ ads/ other items related to noise pollution but only 32 percent could recall.

2) In terms of awareness about pollution ,76 percent of the respondent ascertained that they had seen news/ documentaries/chat shows, ads/reality shows or other items related to air pollution but only 21 percent of the 76 percent could recall properly. About water pollution 51 percent had seen news/ documentaries/chat shows, ads/reality shows or other items related to water pollution but only 28 percent could recall. About soil pollution 74 percent had seen news/ documentaries/chat shows) ads/reality shows or other items related to soil pollution but only 19 percent could recall. About noise pollution 9 percent had read news/ articles/columns/ ads/ other items related to noise pollution but only 17 percent could recall.

3) Of the 71 percent respondents who has access to internet, 26 percent gathered information about air pollution from internet of which 26 percent only could recall, 33 percent gathered information about water pollution from internet of which 15 percent only could recall, 9 percent gathered information about soil pollution from internet of which 15 percent only could recall, 21 percent gathered information about noise pollution from internet of which 14 percent only could recall.

4) Of the 32 percent respondents who listen to radio, 39 percent gathered information about air pollution from news and talk shows of which 44 percent only could recall, 17 percent gathered information about water pollution from news and talk shows of which none could recall, 30 percent gathered information about soil pollution from news and talk shows of which only 29 percent could $\mathrm{p} / \mathrm{r}$ recall, none could recall any information about noise pollution that they have heard from radio. Further it is interesting to note that among the respondents 73 percent confirmed that pollution is a threat to public health.

5) Of the 73 percent who recognized pollution as a cause of health problem in people, 55.8 percent(43 respondents)could identify air pollution as the reason of respiratory 
tract infection, 37.66 percent(29 respondents) pointed out cancer as a result ofpollution,76.6 percent of the respondents identified polluted water as the reason of diarrhea and gastroenteritis problems, 12.3 percent indentified cardiovascular problems as the result of noise pollution, 16.8 percent identified headaches as the result of noise pollution, 40.2 percent identified typhoid as a result of drinking polluted water, 67.53 percent could identify air pollution as the main reason of asthma.

6) Regarding the effectiveness of mass media with regard to awareness about pollution, it is rather surprising to see that though the people of Silchar are quite aware about the hazardous effect of pollution on environment as a whole and general health in particular, majority do not practice environment friendly habits in their day to day life. When asked as to whether any message has recommended behavioral changes in them only 26 percent said that they have started using less plastic an percent stopped dumping household garbage in open place.

\section{CONCLUSIONS}

The aim of the study was to examine the role of media in promoting awareness about pollution and related diseases among the people of Silchar. For accomplishing the objectives of the study survey method was implemented to gather information from the respondents. The study was conducted on the people of Silchar who reside within the Silchar Municipal Jurisdiction. The respondents of the study are primarily youth with good academic and average economic background.

The research revealed that the people of Silchar are averagely aware about the ever increasing problem of pollution. But few has acted upon it. Majority of the respondents could identify the types of pollution along with its causes and effect. The respondents consider skin irritation, respiratory problems and stomach problems as the major affect of pollution in this locality. From the above study, television came out as the most preferred media followed by newspaper. Radio is the least preferred media by the respondents.

It has been found from the study that almost all the respondents has access to modem media (viz. print and electronic media). It is evident from the study that media has played an important role in generating awareness about pollution in Silchar. People could recall information about pollution related issues in media but had not implemented in their life. Another aspect that came out of the study is that most of the respondents are well aware about the issue but very few has actually taken any step to protect the environment apart from waste disposal and less use of plastic bags. The main drawback which came out of the study is the role of media in motivating and pursuing the residents of the town to stand against various issues on pollution. It came out during the study that although people are aware about the lethal effect of the contaminated surroundings they lack the urge and direction to combat it. The local media here also did not apply its potential in initiating any movement or has taken any strong vital step in mitigating the problem of pollution. Lastly, it is suggested that the local media should initiate campaigns along with the local government and health waders to improve the level of awareness and discourage practices that predispose pollution 


\section{REFERENCES}

Atkin, C.K. (1981), Mass Media Information Campaign Effectiveness, In R E. Rice \& W. 1. Paisley (Eds.), Public Communication Campaigns. Beverely Hills, CA Sage Dubois, E. (1999), Environment \& Health, Apple Academics.

Bamji M.S. Murthy PVVS, Rao MV and Dangoria D (2004) Impact of Women Health and Nutirition Entrepreneurs and Mobilizers on Health and Nutrition of Rural Children and Mother's Knowledge and Health Related Practices. Regional Health for 8(1), 92-103.

Jelliffe D.B. (1966). The Assessment of Nutritional Status of the Community. drricanner Gupta J.N.P. and Srivastava R.K. (1998) Profile of Some Statistical Applications in The Field of Medical Science.

Gupta M.C., Mehrotra M; Arora S. and Saran M (1991). Relation of Childhood Mal Nutrition to Parental Education and Mother Nutrition Related KAP. Indian J. Pediatr., 58, 269-274.

Neuzil ,Mark and Kovarik, William(1996): Mass Media and Environmental Conflict America's Green Crusades. Thousand Oaks, CA: Sage Publications.

Pandey, GP. (1999): "Press and Social Change", Manak Publication Pvt Ltd, Delhi.

Pati, RN (1992): "Health, Environment and Development", Ashish Publishing House, New Delhi. 